\title{
Sustainable bis-benzoxazines from cardanol and PET derived terephthalamides
}

Pratibha Sharma ${ }^{\mathrm{a}, \mathrm{b}}$, Bimlesh Lochab $^{\mathrm{c} * *}$, Devendra Kumar $^{\mathrm{b}}$, Prasun Kumar Roy ${ }^{\mathrm{a}^{*}}$

a. Centre for Fire, Explosive and Environment Safety, DRDO, Timarpur, Delhi 110054, India.

b. Department of Applied Chemistry and Polymer Technology, Delhi Technological University, Delhi 110042, India.

c. Department of Chemistry, School of Natural Sciences, Shiv Nadar University, UP 203207, India.

\section{Contents}

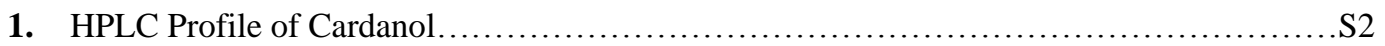

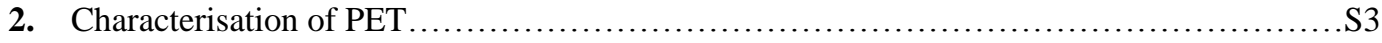

3. Microwave Profile of PET Aminolysis............................................... 4

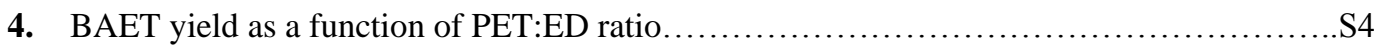

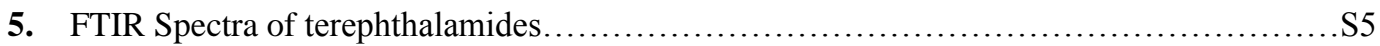

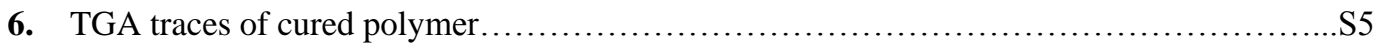

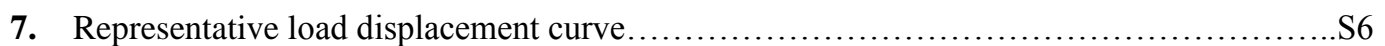

8. Functional groups in polybenzoxazine involved in H-bonding with the contact surface....S6

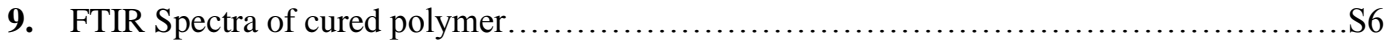


Supplementary information for ACS sustainable chemistry and engineering

\section{HPLC Profile of Cardanol}

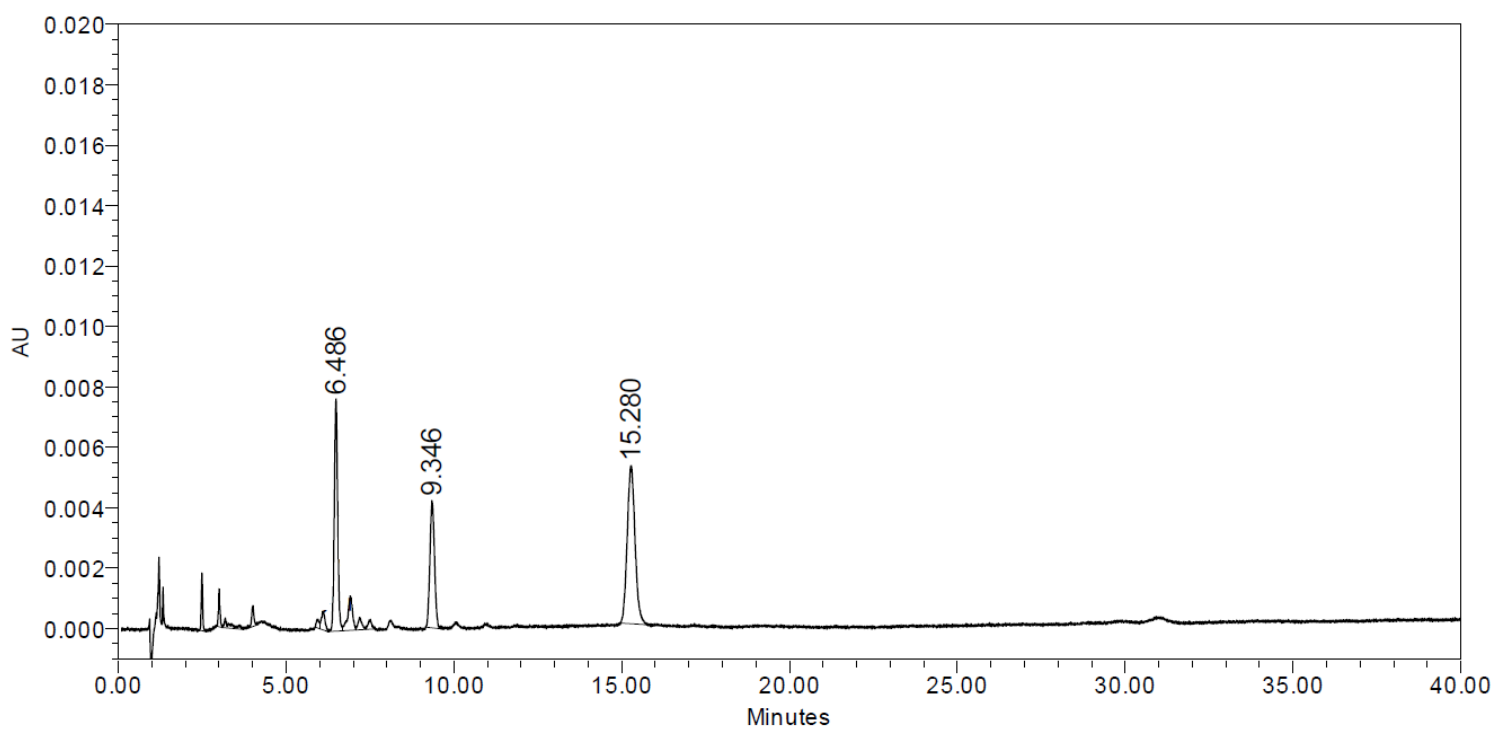

\begin{tabular}{|c|l|c|c|r|}
\hline & Peak Name & RT & Area & \% Area \\
\hline 1 & Peak1 & 2.488 & 5393 & 2.47 \\
\hline 2 & Peak2 & 3.007 & 4036 & 1.85 \\
\hline 3 & Peak3 & 3.188 & 3710 & 1.70 \\
\hline 4 & Peak4 & 4.007 & 3626 & 1.66 \\
\hline 5 & Peak5 & 5.952 & 1654 & 0.76 \\
\hline 6 & Peak6 & 6.082 & 4591 & 2.10 \\
\hline 7 & Peak7 & 6.486 & 53418 & 24.47 \\
\hline 8 & Peak8 & 6.910 & 11384 & 5.21 \\
\hline 9 & Peak9 & 7.189 & 5709 & 2.61 \\
\hline 10 & Peak10 & 9.346 & 40109 & 18.37 \\
\hline 11 & Peak11 & 15.280 & 84683 & 38.79 \\
\hline
\end{tabular}

Figure S1. HPLC chromatogram of cardanol (peak at retention time 6.5, 9.3 and 15.2 minutes are due to cardanol mono-, di- and tri-ene component) [Column: Grace Alltima C18, $150 \times 4.6$ mm, Mobile phase: 80:20:1 Acetonitrile: Water: Acetic acid; Flow rate: $1.5 \mathrm{~mL} / \mathrm{min}$; UV detection at $280 \mathrm{~nm}$ ]. 
Supplementary information for ACS sustainable chemistry and engineering

\section{Characterisation of PET}

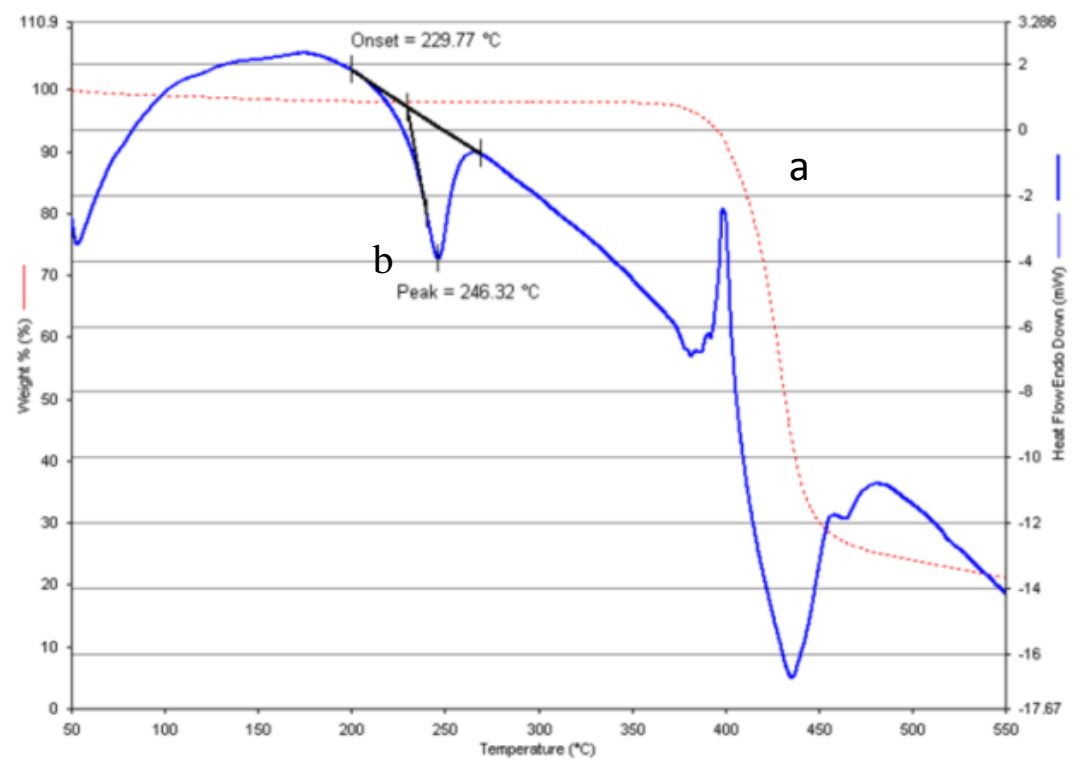

Figure S2: (a) TG and (b) DSC trace of PET

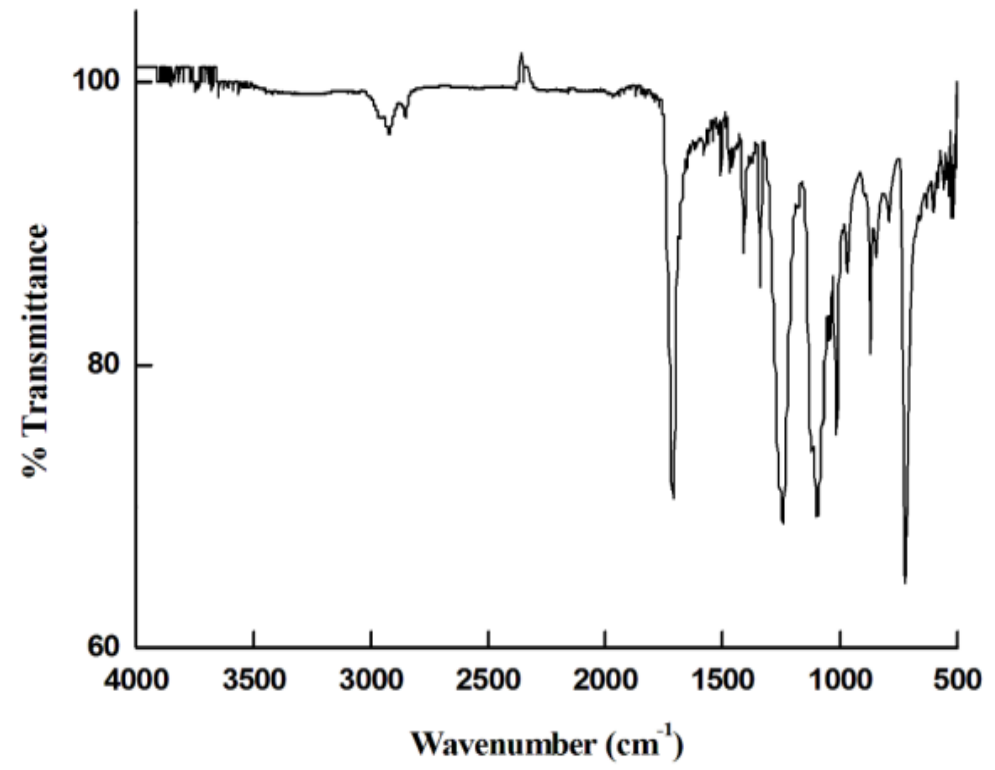

Figure S3: FTIR of PET 
Supplementary information for ACS sustainable chemistry and engineering
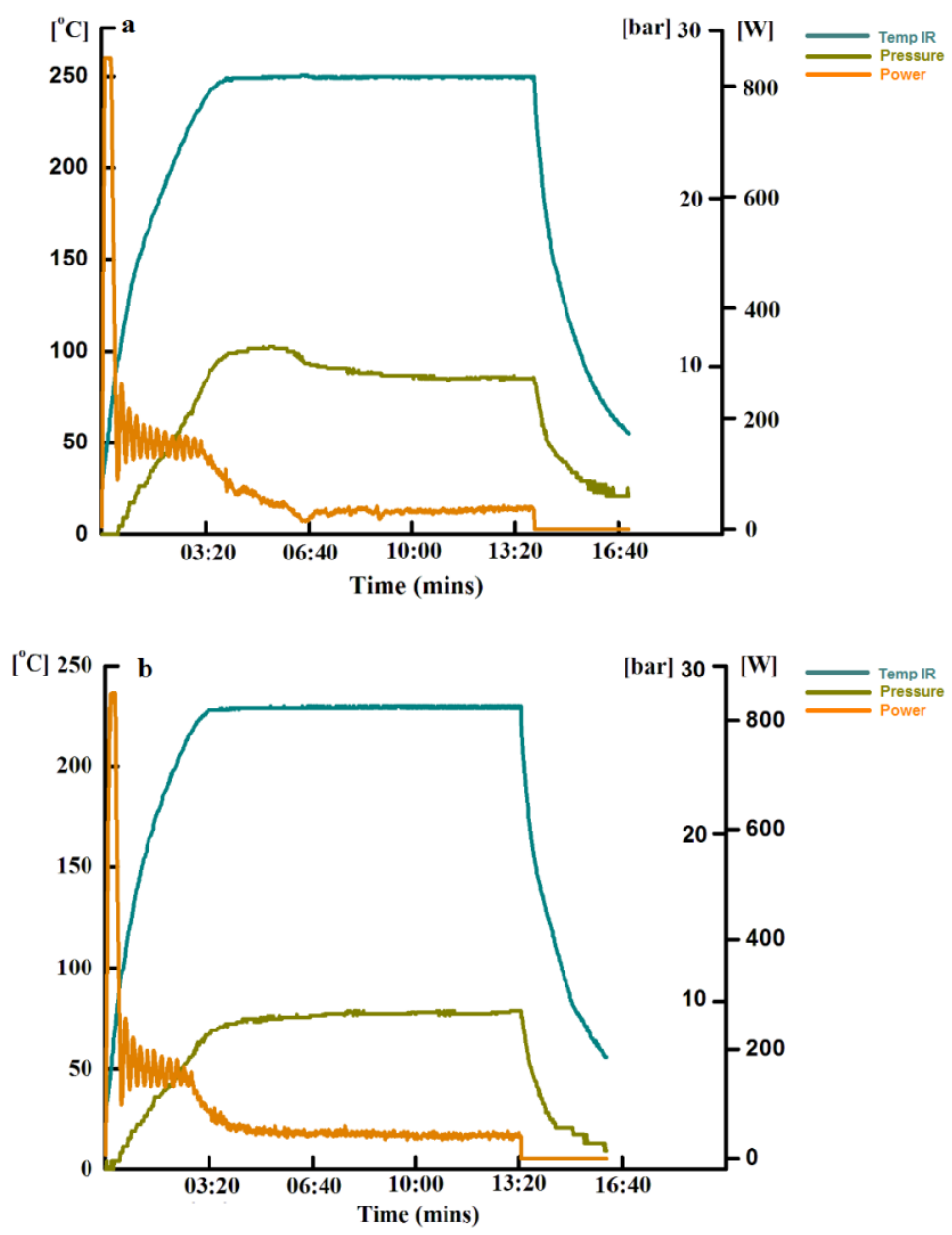

Figure S4: Microwave Profile of PET aminolysis at temperature a) 250 and b) $230{ }^{\circ} \mathrm{C}$.

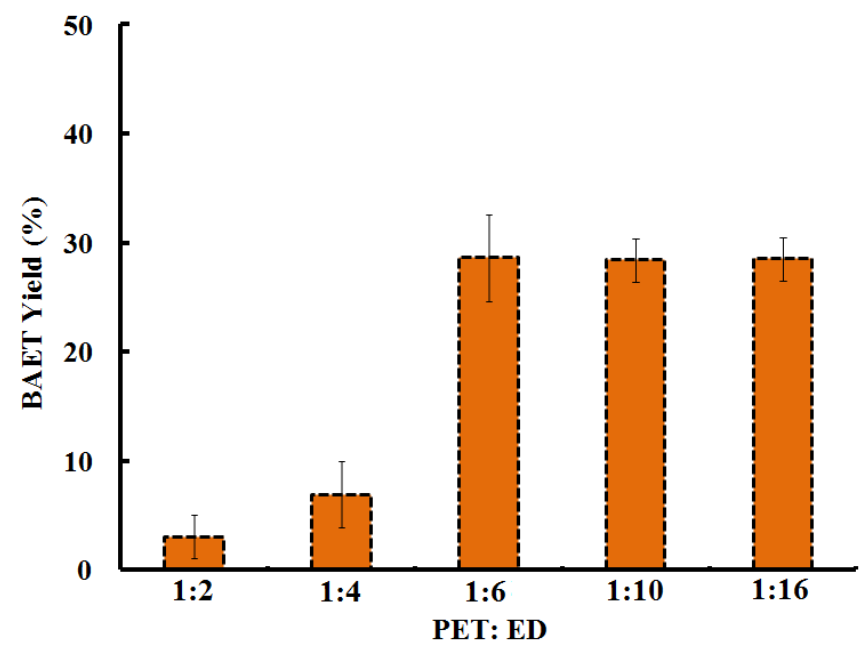

Figure S5: BAET yield as a function of PET:ED ratio (reaction temperature $250^{\circ} \mathrm{C}$, reaction time $10 \mathrm{~min}$ ) 


\section{Supplementary information for ACS sustainable chemistry and engineering}

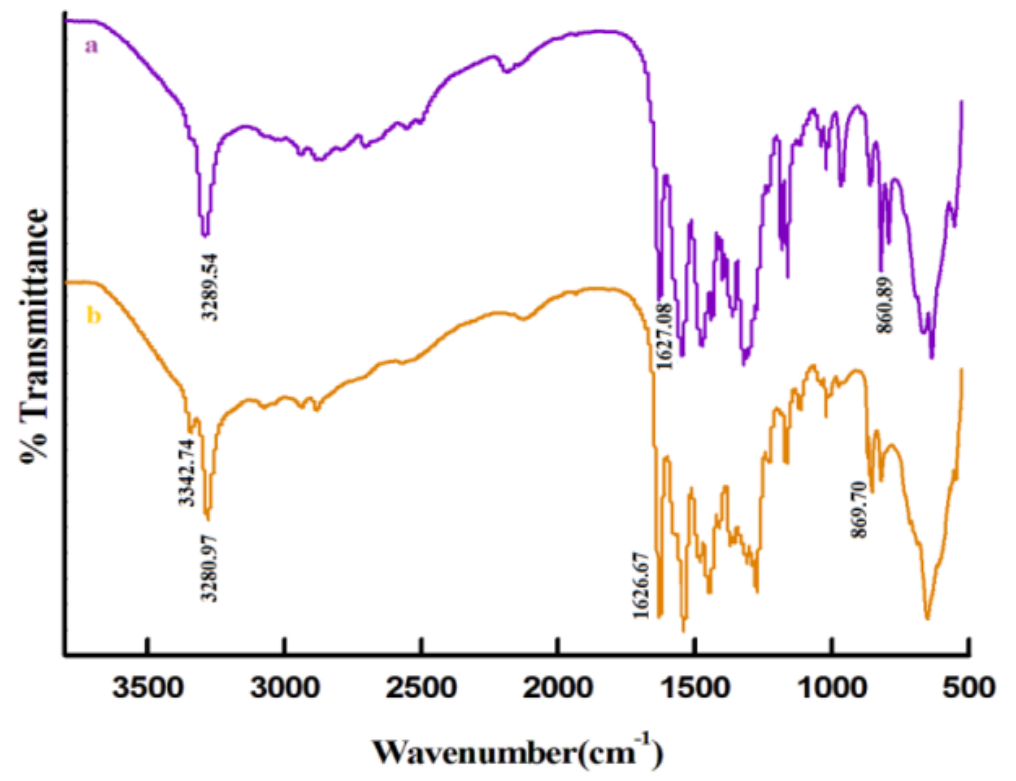

Figure S6: FTIR Spectra of a) AOET b) BAET

The difference in the relative intensity of the absorbance associated with primary $\left(1^{\circ}\right)$ and secondary $\left(2^{\circ}\right)$ amine is quantified as $\left(\frac{\mathrm{Abs}_{\mathrm{NH}_{2}, 1^{0}}}{\mathrm{Abs}_{\mathrm{NH}, 2^{0}}}\right)$

which is 0.57 for BAET and 0.49 for AOET. This clearly indicates that the concentration of $1^{\circ}$ amine in BAET is higher than in AOET, in line with the structure presented in scheme 1 (main text).
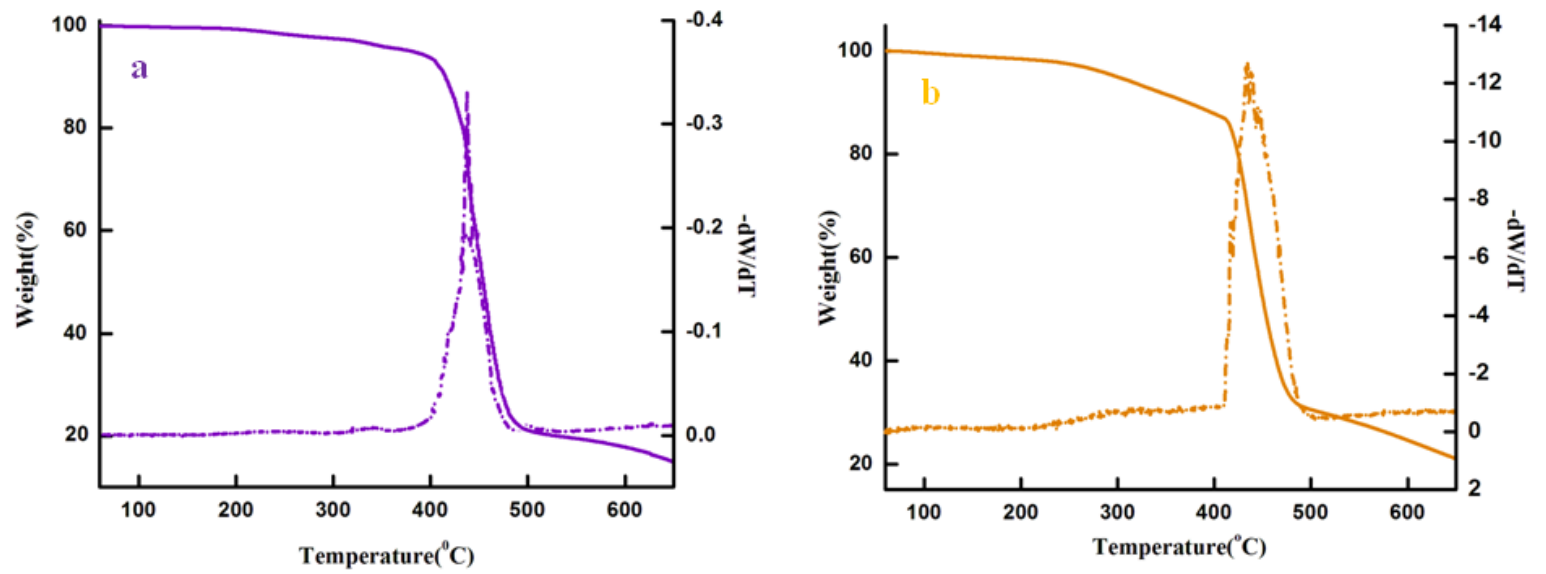

Figure S7: TGA traces of cured a) C-AOET b)C-BAET 
Supplementary information for ACS sustainable chemistry and engineering

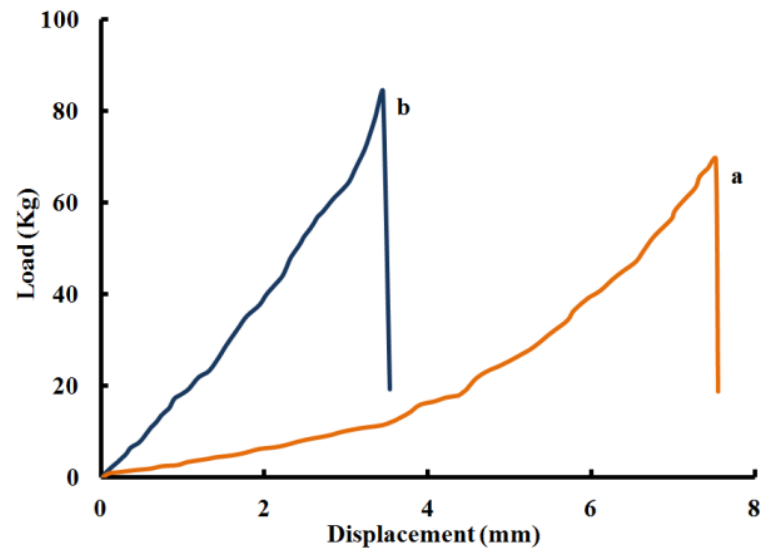

Figure S 8: Representative load displacement curve of a) C-AOET and b) C-BAET

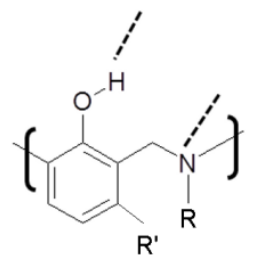

Figure S9: Functional groups in polybenzoxazine involved in H-bonding with the contact surface

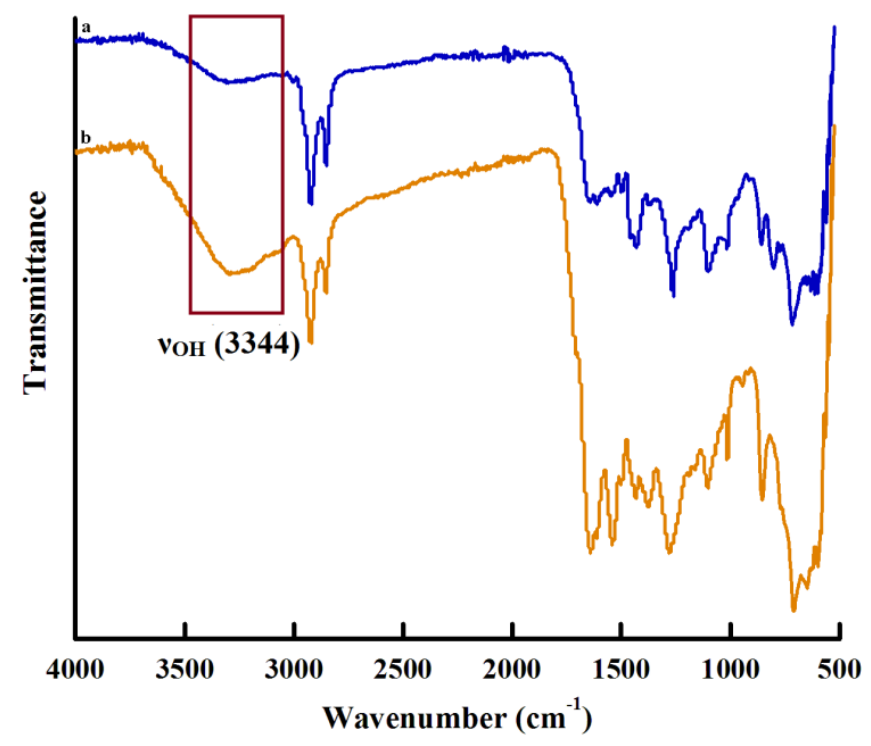

Figure S10: FTIR Spectra of cured a) C-AOET b) C-BAET 